\title{
Rectification and stabilization of the foundation as an opportunity in reference to preventing construction failures as regards transformer station facilities located on a wind farm
}

\author{
Rafat Kuszyk ${ }^{1, *}$, Anna Gniwek ${ }^{2}$, and Krzysztof Walczak ${ }^{2}$ \\ ${ }^{1}$ Warsaw University of Technology, Faculty of Civil Engineering, Al. Armii Ludowej 16, \\ 00-635 Warsaw, Poland \\ ${ }^{2}$ HGS Sp. z o.o., ul. Puławska 26/33, 02-512 Warsaw, Poland
}

\begin{abstract}
In the paper, the results of inclination measurements of 9 transformostation objects are presented. The inclination was caused by uneven settlement of the ground below the foundation level. The causes of uneven settlements are described and the method of performed rectification works is presented.
\end{abstract}

\section{Introduction}

After the first year of operation the wind power facility consisting of 9 turbo generator masts and the corresponding number of transformer stations became an object of tests and analyzes. The aforementioned verification resulted from the occurrence of uncontrolled subsidence concerning transformer station facilities in all locations and, consequently, their tilting. According to geodetic measurements, all 9 tested transformer station masts indicated in [1] and [2] tilted towards the foundations of turbine masts. The measured tilt ranged between $2 \div 4.5^{\circ}$. At the same time one could observe relative height difference as regards the corners of the foundation slabs within the limits ranging from 11 to $56 \mathrm{~mm}$. Due to the dynamic character of the phenomenon and the fact that a further, uncontrolled tilt could threaten the safety of transformer station operations and could result in shutting down the entire wind farm, one made a decision to discontinue further tilting of the transformer objects and rectify their foundations immediately. The task involving the repair was to be performer during normal operations of the power plant with the temporarily excluding only the object which was being repaired at that moment. The discussed task was assigned to the company HGS Sp. z o.o. As part of the aforementioned order the company conducted necessary geological and geotechnical tests of the ground located in the area where works were carried out, prepared a construction repair project at the executive level, conducted all renovation works provided for in the project using its own means, introduced a control work program, performed the first base measurement applicable later during the monitoring process realized by the investor.

\footnotetext{
*Corresponding author: r.kuszyk@il.pw.edu.pl
} 
Observations were conducted systematically for two years after the completion of the repair and their results indicate that the facilities which underwent the repair are completely stabilized. Consequently, the issue was eliminated for good.

\section{Description of the issue and the reasons explaining the occurrence of the issue based on conducted tests, measurements and analyzes}

According to the diagnosis conducted in May 2015 by experts and designers working for the company HGS [1], tilting of transformer stations was caused by uncontrolled, uneven subsidence of the ground located under the objects. This, in turn, resulted from placing the foundation directly on plastic and soft plastic substrates. The plasticity level of the substrate amounted to $\mathrm{IL}=0.25 \div 0.60$. Objects were located too close to the edge of deep excavations made for the turbo generator masts foundations. One applied small distance between these objects, in extreme cases this distance amounted to "zero", to achieve savings as regards the length of low and medium voltage transmission cables. Moreover, the manner of setting prefabricated reinforced concrete transformer station containers was not consistent with high standards applied in wind energy production. This involved the removal of the ready-made object from the transport platform using the crane and placing it on the surface. The surface consisted of hardened levelled concrete floor with thickness $5 \div 10 \mathrm{~cm}$ and the walls were covered with soil from excavation executed under the mast reaching the height of approx. $1.0 \mathrm{~m}$ above the foundation level.

The soil in the substrate (clay sands and sandy clays) was tested up to a depth of $1.0 \div 1.2 \mathrm{~m}$. The banks were made of clay sands and sandy loams which came from excavations under the foundations of masts for wind turbines and turbine sets. Based on conducted research one can conclude that there is high probability that these soils were soaked while being stored on the bing. Moreover, they were not brought to the required moisture level prior to being built into the bank. Consequently, they are not thick enough as well.

Simultaneously one discovered that the guidelines covered by the construction project did not provide clear requirements as regards the parameters concerning the cohesive material incorporated into the bank. The range of soil weight was broad amounting to $\gamma=16.5 \div 20.0 \mathrm{kN} / \mathrm{m}^{3}$ provided for in the project. This includes both favoured soils such as hard plastic soils $\left(\mathrm{I}_{\mathrm{L}}=0.10 \div 0.25\right)$ as well as weak soft plastic soil $\left(\mathrm{I}_{\mathrm{L}}>0,50\right)$.

Case study within the aforementioned project included a case-by-case analysis of tilting in reference to transformer station objects due to the displacement of soil under the block foundation of a wind turbine.

During their analysis the authors applied FEA-based calculation programs due to the proximity of both objects as well as significant static and dynamic loads of foundations for wind turbines. The result of these calculations did not confirm the possibility of soil displacement from the foundation of the turbine if one applied DSM columns in the conditions of execution at the bottom of the foundation excavation. Naturally the authors assumed the correct performance of such columns.

Nevertheless, the impact of foundation trenches directly onto the foundations of the transformer station reached the depth of $3.0 \div 3.5 \mathrm{~m}$ below ground. During the foundation works one could observed relaxation and loosening of the structure surrounding the soil excavation in this area. For that reason the method of making backfills and compaction is extremely significant. The type and condition of the charging material prove to be important as well. 
Taking what has been stated the above into consideration it was necessary to place them on micro-piles in order to stop the process of uncontrolled settling of the substrate under container transformer objects. While passing through the weak-bearing layers of plasticized clays these micro-piles transfer the loads generated by the object and the deforming soil to supporting layers of the soil with undamaged structure located deeper.

Table 1 presents relative differences as regards the foundation levels of the foundation slab corners in reference to each of the nine transformer stations. These measurements were obtained during geodetic surveys. The accuracy level is $1 \mathrm{~mm}$.

Measurements of 9 objects which tilted due to uneven settlement of the substrate below the foundation level required quick geo-engineering activities. The aforementioned activities were aimed at discontinuing the uncontrolled subsidence process and restoring objects to the originally planned vertical and horizontal positions.

Table 1. Relative differences as regards the foundation of the transformer station foundation slab level $1 \div 9$.

\begin{tabular}{|c|c|c|c|c|c|c|c|c|c|c|}
\hline \multirow{2}{*}{$\begin{array}{l}\dot{0} \\
z \\
0 \\
\text { 至 } \\
\underline{\Omega}\end{array}$} & \multicolumn{2}{|c|}{ 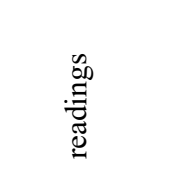 } & \multirow{2}{*}{$\frac{\vec{D}}{\frac{\vec{J}}{J}}$} & \multirow{2}{*}{ 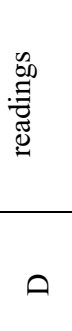 } & \multirow{2}{*}{ 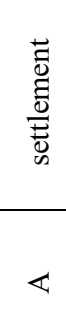 } & \multirow{2}{*}{ 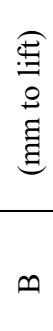 } & \multirow[b]{2}{*}{$U$} & \multirow[b]{2}{*}{0} & \multirow{2}{*}{ 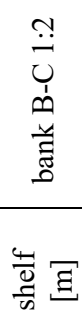 } & \multirow[b]{2}{*}{$\begin{array}{l}\vec{E} \\
.000 \\
\vec{E}\end{array}$} \\
\hline & $\varangle$ & $m$ & & & & & & & & \\
\hline 1 & 911 & 949 & 977 & 939 & 66 & 28 & 0 & 38 & 1.6 & 0.85 \\
\hline 2 & 855 & 932 & 966 & 889 & 111 & 34 & 0 & 77 & 1.6 & 0.80 \\
\hline 3 & 909 & 952 & 965 & 922 & 56 & 13 & 0 & 43 & 1.6 & 0.80 \\
\hline 4 & 463 & 556 & 567 & 474 & 104 & 11 & 0 & 93 & 2.5 & 0.80 \\
\hline 5 & 625 & 610 & 651 & 666 & 41 & 56 & 15 & 0 & 2.5 & 0.80 \\
\hline 6 & 854 & 906 & 911 & 859 & 57 & 5 & 0 & 52 & 3.6 & 0.90 \\
\hline 7 & 928 & 966 & 962 & 924 & 38 & 0 & 4 & 42 & 1.3 & 0.75 \\
\hline 8 & 190 & 261 & 273 & 202 & 83 & 12 & 0 & 71 & 1.6 & 0.55 \\
\hline 9 & 252 & 285 & 303 & 270 & 51 & 18 & 0 & 33 & 1.7 & 0.80 \\
\hline
\end{tabular}



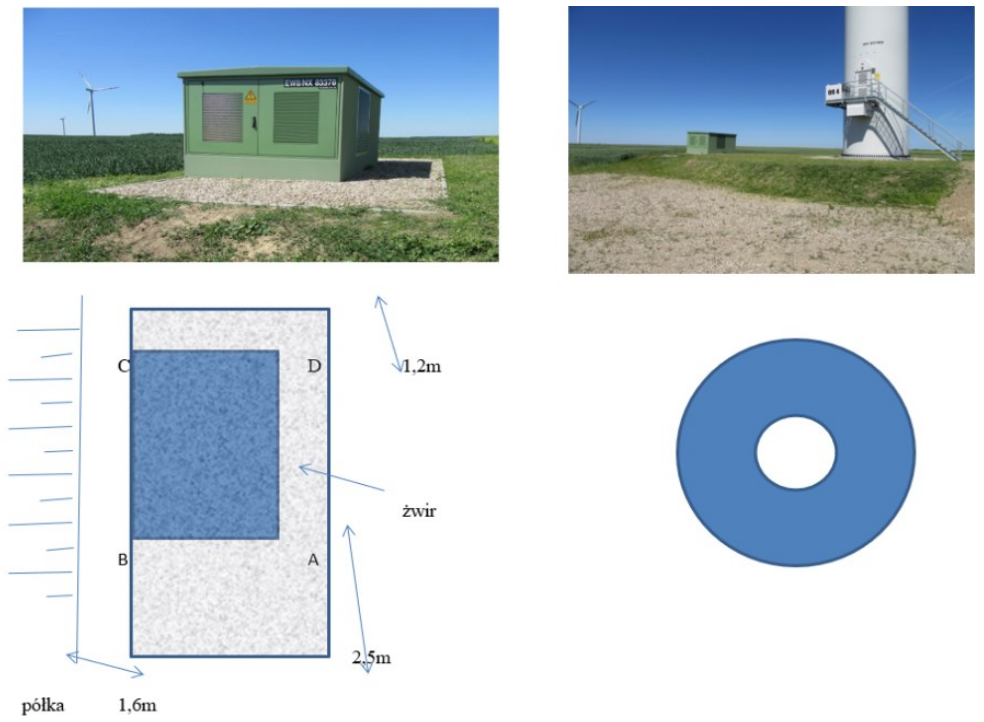

Fig. 1. Diagram presenting transformer station and wind turbine system.

\section{Characteristic features (description) of transformer stations}

As regards the aspect of construction the transformer stations were made of reinforced concrete prefabricated rectangular boxes with bottom and flat roof plates which were $15 \mathrm{~cm}$ thick. The walls were $11.5 \div 13 \mathrm{~cm}$ thick. The flat roof slab constituted a separate element attached to the walls. It opens from the box top using steel anchors. The designers applied internal partitions. Their function was to stiffen the boxes and separate the spaces located inside and responsible for the functioning of the objects following their intended purpose. Lower corners of longer prefabricated transformer boxes walls were cut at an angle of about $45^{\circ}$. The cut followed the slanted strip of shorter walls where the sealed cable entries NN and SN were located. The insulated cables were to run in the ground at a depth of $0.9 \div 1.5 \mathrm{~m}$ below ground level (bank). The cables run towards the masts (NN) and field (SN). Sockets left after anchors used for transporting prefabricated elements were located on 4 vertical edges of longer substation walls, at a distance of $7.5 \mathrm{~cm}$ from these edges. One of the aforementioned anchors was used to fasten the earthing installation from the hoop iron. The cavity of sockets under the surface of the bank varied within the range of $17 \div 36 \mathrm{~cm}$.

Following the design the objects were to be placed directly on the banks with different degree of compaction amounting to $0.5<\mathrm{I}_{\mathrm{D}}<0.7$. They were also placed on a clayey soil with an intact structure which was found in this area. Nevertheless, the proximity of the location as regards transformer stations and excavations for the foundations of turbo generator masts, was certainly not favourable. This situation constituted a probable cause of uneven settlement of the ground under the transformation station objects resulting from stress relief. The difference in the foundations of masts foundations and transformer station amounted to $2.5 \div 3.5 \mathrm{~m}$.

The foundations of the transformer station were to be recessed $80 \div 100 \mathrm{~cm}$ below the ground level. In each case it involved a ground bank obtained due to the mast foundation excavation. Consequently, each object consisting of a mast and transformer station constituted an "island", with a diameter of approx. $50 \div 70 \mathrm{~m}$, elevated above the surrounding area to a height reaching about $80 \mathrm{~cm}$. One executed technological roads providing access to large means of transport and construction machines on bank with a sand gravel within $30 \div 100 \mathrm{~m}$ from the facilities. 
Outcrops were realized as part of the research work. No foundations were found in the substrate, at the level of the bottom of the foundation slabs. The presence of artificially created backfilling layers improving the conditions of their foundation was noticed.

One applied $1.5 \mathrm{~m}$ wide belt with concrete pavement rims around each transformer station. It was spilled with sorted crushed stone with a granulation of $8 \div 30 \mathrm{~mm}$. The thickness of the breakstone layer amounted to $10 \div 15 \mathrm{~cm}$.

During the inspection conducted while preparing repair documentation, the walls, bottom and ceilings of the prefabricated transformer station were flat, undeformed despite the deviations from the vertical position as regards all enlisted elements. The surfaces of the walls and flat roof were did not crack. They were smooth. The part located above the ground was painted with green paint. As regards the part located below - the walls had a natural colour of the concrete and a smooth texture, there were no pits, crampons and other defects.

Metal window and door joinery elements had no visible signs of damage or deformation.

\section{Description of project solutions}

Research and analysis conducted by the authors in the spring - summer of 2015 enabled establishing a thesis concerning the causes of uncontrolled tilting of the transformer station as well as providing manners of discontinuing this process and restoring the original location of the transformer. The authors indicated uneven subsidence of the substrate under the foundations of the transformer station as the reason for tilting. The discussed process was caused by the loosening of the soil surrounding the deep, wide foundation excavation, under the turbine mast which was located too close. The designers undertook the fastest construction solutions possible which could have been conducted without delay resulting from mobilization of heavy equipment and the implementation of complex technologies as the area of loosening the ground caused by its relaxation and weather related phenomena accompanying earthworks with a long period of implementation could have extended over time. Such a process, in turn, could have caused further settlements resulting in more tilting of objects located on it.

The project presents a manner of discontinuing further settlements of facilities on their foundation on Titan drilled and injected micro-piles. They ordered straightening (plumbing and levelling) applying controlled lifting of the foundation slab corners using steel beams supported by micro-piles located at their edges. The described procedure was conducted using hydraulic cylinders with load capacity and proper impact adjusted to the existing conditions. The comprehensive technology of stabilizing and rectifying objects utilized the assumption of using small-size machines and devices which are able to operate and move manually by people. The use of heavy machines and equipment was to be limited.

Measured tilt of 9 relocating objects, caused by uneven settlement of the substrate due to uneven settlement of the ground below the foundation level required quick geo-engineering activities. These activities were aimed at discontinuing the process of uncontrolled subsidence and restoring objects to their originally designed vertical and horizontal positions.

The technological activities presented below were repeated in reference to all 9 transformer stations. These activities were implemented following the order indicated below:

$\checkmark$ manual removal of $20 \mathrm{~cm}$ top layer of gravel from the area around the object within a $1.5 \mathrm{~m}$ wide belt. The belt was limited by concrete pavement rims, a heap was formed outside the area where the machines operated,

$\checkmark$ excavating and disassembling concrete edgings, this was combined with preparation and securing material which was to be demolished and be reused later, 
$\checkmark$ manual execution concerning grooves, vertical walls up to depth of $20 \mathrm{~cm}$ below the foundation level as regards the objects with a depth of $0.7 \mathrm{~m}$ protecting the stability of the walls, depositing the soil on the bedding,

$\checkmark$ pressing steel pipes with a rectangular cross-section, dimensions $160 \times 160 \times 3 \mathrm{~mm}$, length $2500 \mathrm{~mm}$ from the bottom of excavations, from excavation bottom level, removal of spoil from its interior,

$\checkmark$ execution of 4 drilled and injected micro-piles using Titan, Gonar or equivalent 40/20/115 system, total length of $7.0 \mathrm{~m}$ each from the level of a wooden platform over excavations, reinforcement, concreting using a mixture of C16/20 (B20), a ready dry mixture was used to be applied on the construction,

$\checkmark$ puling steel beams from $2 \times C 140 \mathrm{~mm}$ rolled section stretched through a pipe, paint coating was applied to protect from corrosion, permanent support using system sheets and Titan, Gonar system nuts or equivalent,

$\checkmark$ filling the inside of a rectangular pipe with cement grout $-\mathrm{w} / \mathrm{c}=0.4$, completed using pressure injection, after fastening the ends of the pipe with concrete and filling the venting valve,

$\checkmark$ narrow, $20 \mathrm{~cm}$, unearthed object around the perimeter reaching the level of LN and MV power cables,

$\checkmark$ levelling the base of the facility by lifting single-sided steel beams in casing pipes step by step, this activity required manual high-pressure pump and hydraulic lifting machines, their load capacity amounted to $250 \mathrm{kN}$, at the same time overclocking Titan, Gonar or equivalent system sheets which served as the subject permanent support, conducting continuous geodetic control, 4 benchmarks were placed on the wall surface of the station,

$\checkmark$ concreting the beams in the excavation pit using C16/20 concrete mix (B20), injecting filling into the voids located under the substitute foundation plate (cement grout),

$\checkmark$ backfilling excavations as well as the reconstruction of the area around the excavation to restore the original condition (backfilling excavations with soil compaction from excavations, establishing margins and spreading gravel). 

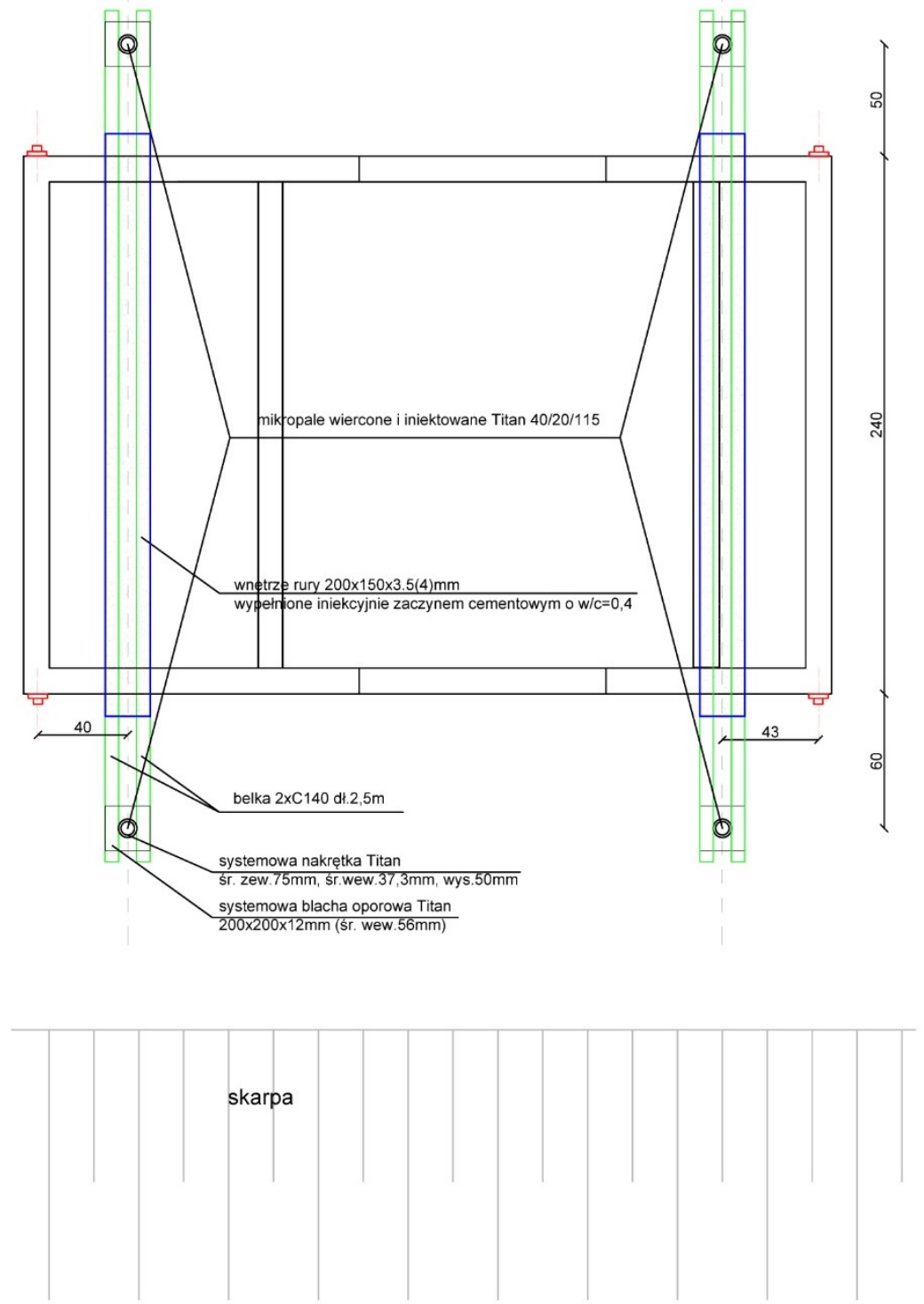

Fig. 2. Projection of the rectified transformer station according to [2]. 


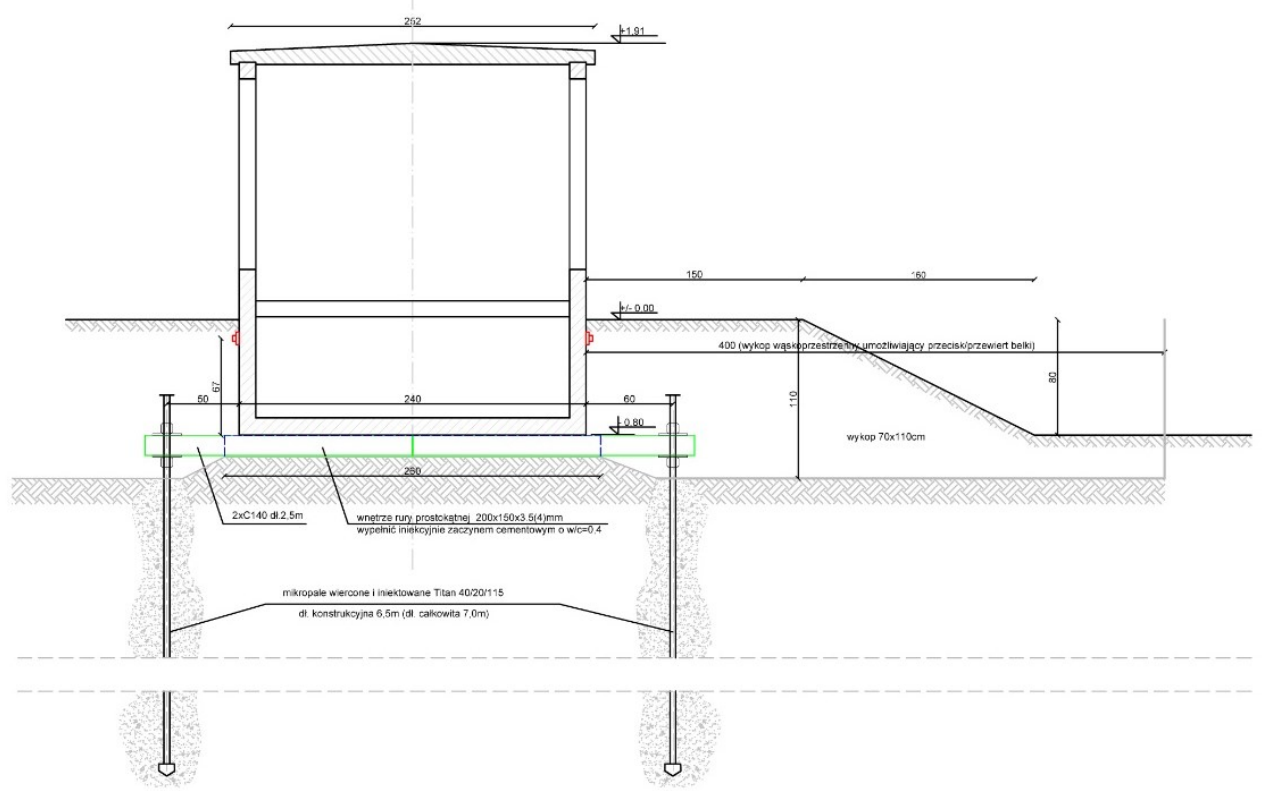

Fig. 3. Cross section according to [2].

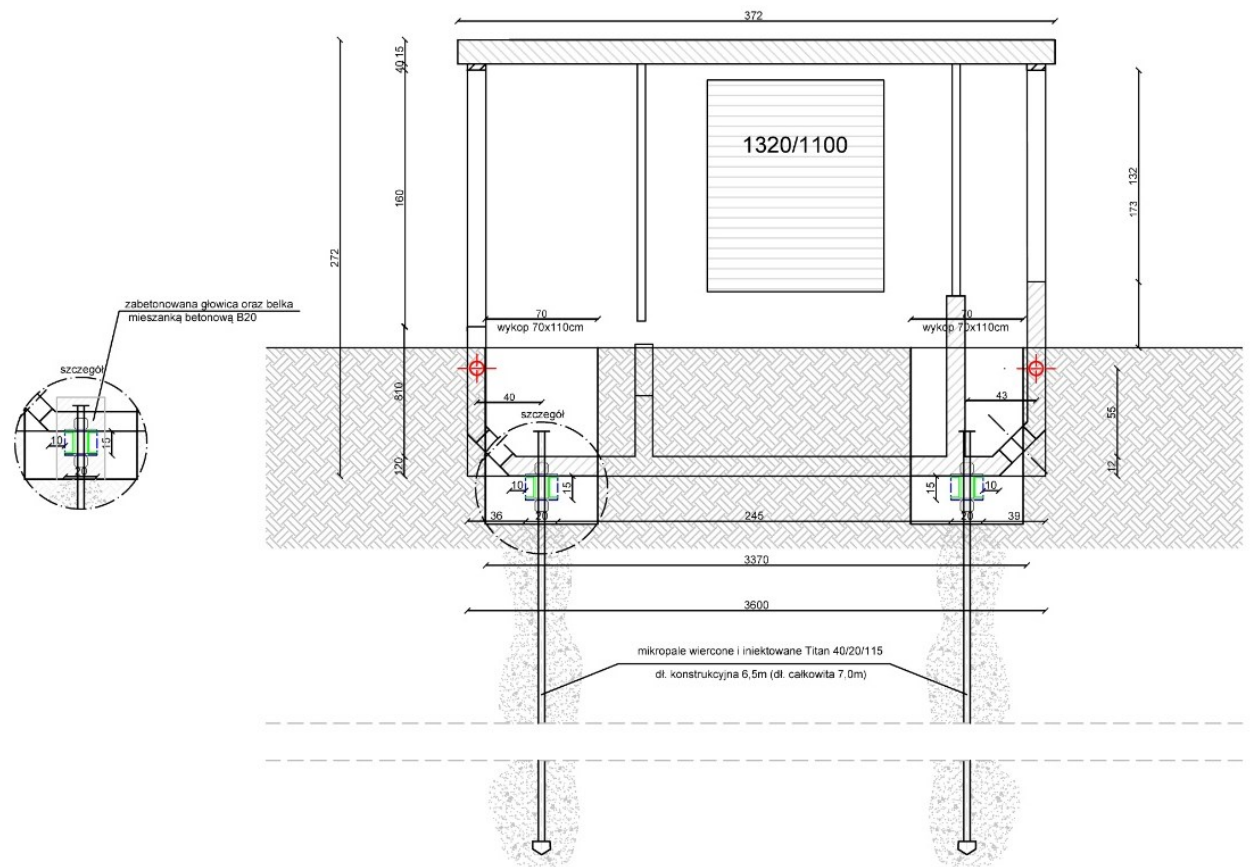

Fig. 4. Longitudinal section according to [2]. 


\section{The course of works aimed at restoring the original location of transformer station}

The activities indicated below were conducted in reference to all nine relevant transformer stations:

$\checkmark$ Geodetic measurements concerning the height as regards the bank area around the relevant transformer station,

$\checkmark$ Scraping the covering layer of gravel and preventing its contamination with soil,

$\checkmark$ Excavation of the transformer station in four corners as well as along the installation edge reaching the depth of about $20 \mathrm{~cm}$ below the foundation level,

$\checkmark$ Cleaning the bottom surface of the bottom transformer station plate, the widths of approximately $30 \mathrm{~cm}$ along the installation edges, by cutting concrete balance layers, thickness ranging from 5 to $15 \mathrm{~cm}$,

$\checkmark$ Installation of temporary rain covers over the facility, this included excavations and soil deposits, polypropylene tarps $6 \times 4 \mathrm{~m}$, coniferous timber $60 \times 40 \mathrm{~mm}$ and stranded cables $\Phi 4.5 \mathrm{~mm}$ were applied.

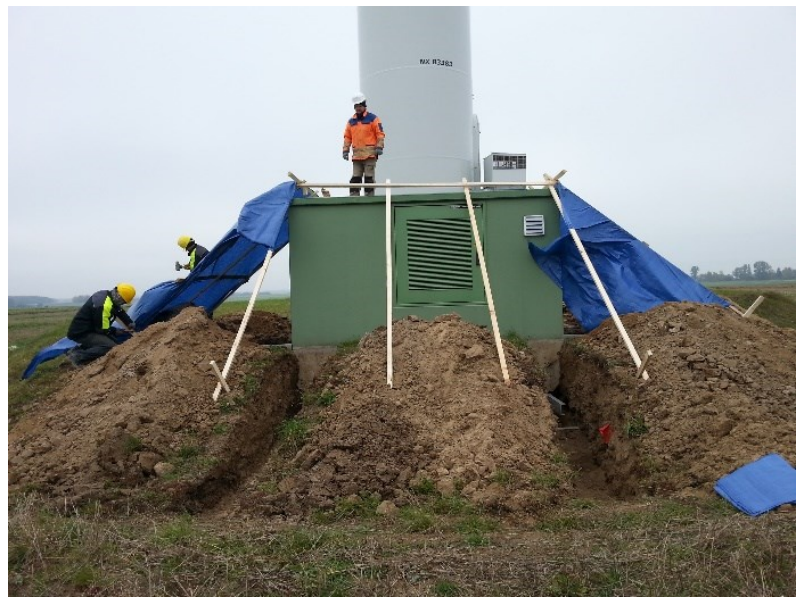

Fig. 5. Rainwater protection concerning the transformer station area.

$\checkmark$ The purchase and prefabrication of steel construction, shielding and auxiliary elements from a nearby plant, the purchased elements included:

- steel beams with a normal channel bar 140 of $4000 \mathrm{~mm}$,

- steel pipes with a rectangular cross-section of 200x150x4 mm, length $2500 \mathrm{~mm}$,

- steel pad consisting of 8 and $4 \mathrm{~mm}$ thick sheets, their dimensions of 200x100 mm,

- steel clamps made of rue 200x150x4 mm width $100 \mathrm{~mm}$ on the ends of steel beams. The prefabrication realized in the factory conditions included the following activities:

- cutting each of the aforementioned elements to meet the desired dimension,

- cleaning to $\mathrm{Sa} 2 \frac{1}{2}$ degree,

- applying a paint coat consisting of a primer and one or two anti-corrosive epoxy paint topcoats applied twice or three times (Tikkurila Temacoat GPL-S Primer as well as Temadur Paint System Temathane 50). Thickness of coating in case of casing pipe amounts to $220 \mu \mathrm{m}$ steel, as regards U-shaped elements, sheets and 
clamps cannot be less than $120 \mu \mathrm{m}$. Pneumatic spray was used for applying the coating.

$\checkmark$ Displacement of steel pipes with cement mortar stabilization under dug edges of transformer station,

$\checkmark$ Inspection and verification concerning the ground under transformer station in reference to compliance with the project, it was done by implementing manual geological holes reaching the depth of $6 \mathrm{~m}$ along with the documentation of these holes,

$\checkmark$ Location and assembly of 4 items/Titan 40/20/115 micro-piles onto station in the ground, average length of $7 \mathrm{~m}$, applied technology observes ITB Technical Approval no. AT-15-6416-2010.

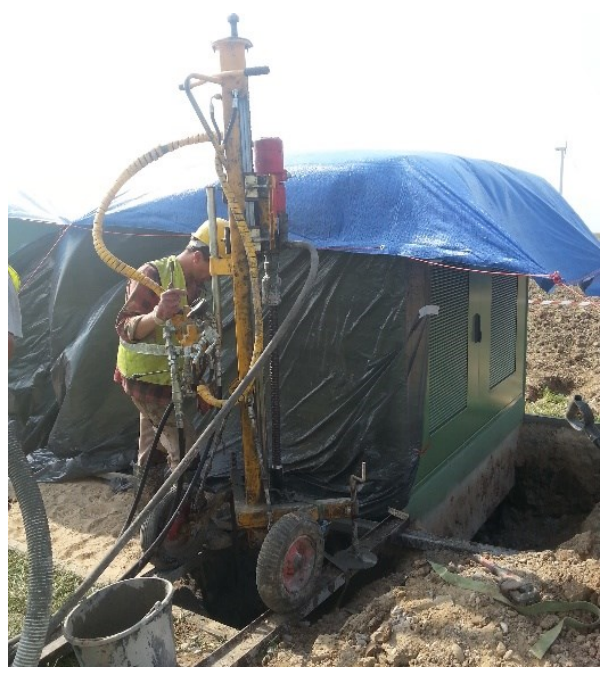

Fig. 6. Installation of micro-piles.

$\checkmark$ Installation of $2 \mathrm{xC140}$ steel beams in a steel protective tube, pre-support of the edges using Titan sheets and caps, initially lifting the lower nuts reaching the limit of human strength.

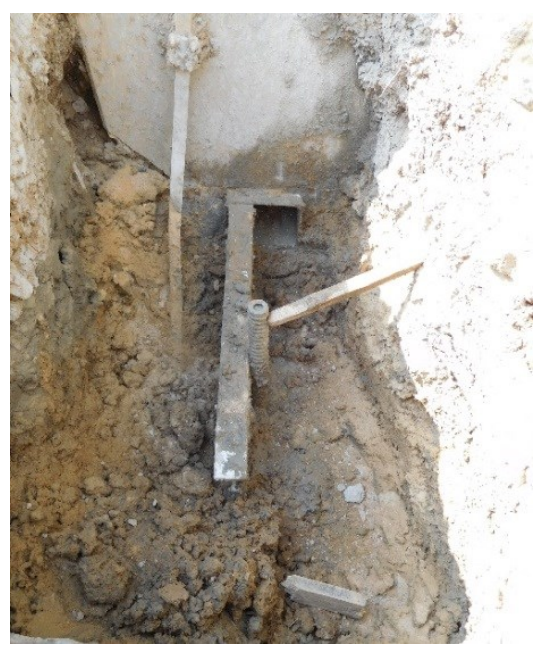

Fig. 7. Installation of steel beams $2 \mathrm{xC} 140$.

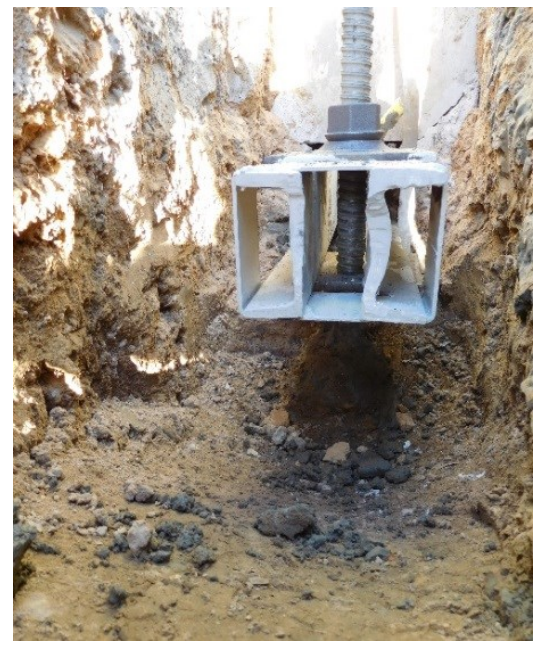

Fig. 8. Supporting support beams on micro-piles. 
Filling of the inside of steel pipes with moved beams $2 \mathrm{xC} 140$ by injecting cement $\mathrm{w} / \mathrm{c}=0.5$, the procedure was done using injection tubes sealed on both sides using mineral mortar CX-15 as well as Atlas Fitter T5,

$\checkmark$ 7-day technological break which is necessary in reference to hardening the cement stone, covering micro-piles, used for performing works concerning subsequent transformations,

$\checkmark$ Continuing rectification works by installing measuring indicators on the facility walls, applying the scale of $1 \mathrm{~mm}$ and conducting measurements of the corners of the facility at the reference points, the measurements were conducted applying control benchmarks indicated by an authorized surveyor,

$\checkmark$ Preparation of the substrate for the servomotors, this was obtained by preparing shallow cement-gravel foundations (reinforced with steel rods Ø12) covering an area of 30x30 cm at the depth of $1 \mathrm{~m}$,

$\checkmark$ Placing the servomotors under the steel beams following the instructions of the Works Manager, procedure starts with lifting the corners located at the lowest points by controlled pressure increase using manual high-pressure hydraulic pumps with simultaneous continuous control of the observed transformer movements on two levels adjusted diagonally as regards the object,

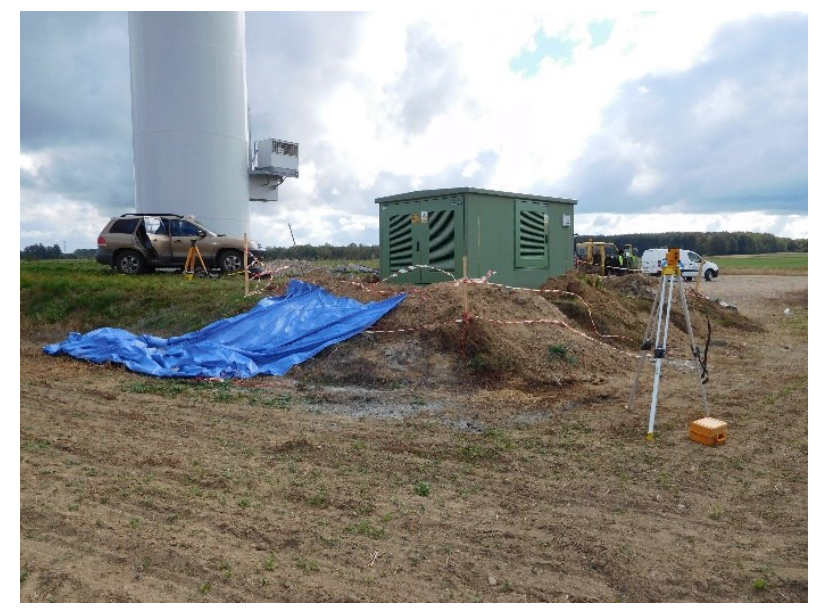

Fig. 9. Control of lifting using two levelling instruments.

Conducting rectification works involving the change of the pressure and the point of applying the forces in the servomotors. At the same time one conducted overlocking and locking of nuts and system plates located on the micro-piles until one obtained the effect of levelling the transformer station or achieved the best effect due to the limited tension of energy cables originating from the ground and entering the inside of the transformer station. Cable tension was tested visually as well as based on the behaviour of nuts on tight cable glands passing through the wall of the facility. Loosening/dislocating the nut served as a signal to discontinue rectification and repair the cable gland. The repair concerned three objects designated with numbers EW8, EW7 and EW6. The process involved unscrewing the cable gland, correcting the position in the hole, applying permanently plastic putty peripherally, then screwing the nut back onto the cable gland. Repair work concerning tight cable routes was conducted based on the request and under supervision of the Representative of the Investor. 


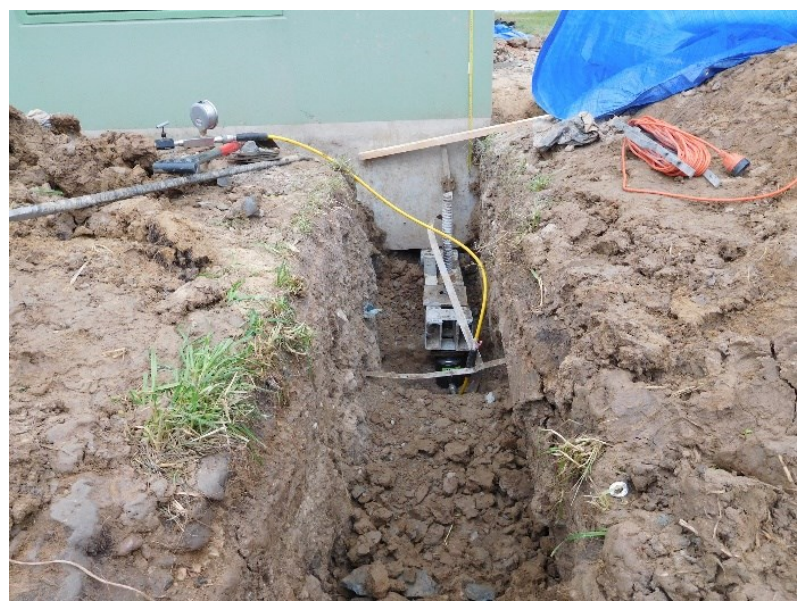

Fig. 10. Lifting the corner using a hydraulic cylinder and a manual pump.

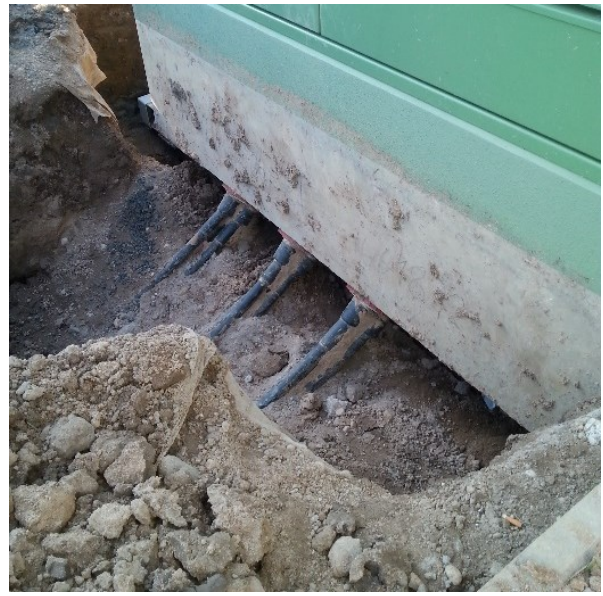

Fig. 11. Tightening power cables.

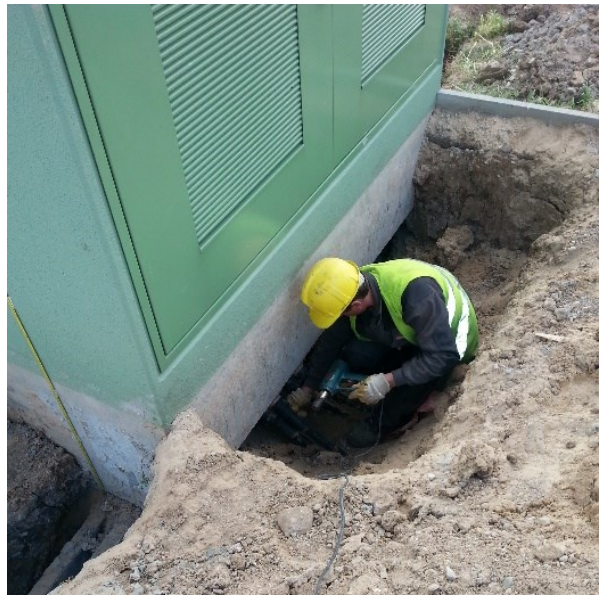

Fig. 12. Sealing cable entries after lifting.

Altitude control measurements conducted 24 hours after the termination of rectification activities and support on micro-piles,

$\checkmark$ Concreting steel ends of $2 \mathrm{xC} 140$ beams within formworks to establish a buffer around steel min. $7 \mathrm{~cm}$ using a mixture of C 20/25 W concrete with an admixture of ANTIFROST 45 application of corrosion inhibitor at the construction site using a concrete truck, the amount of $12 \mathrm{~kg}$ per $1 \mathrm{~m}^{3}$ of mix. 


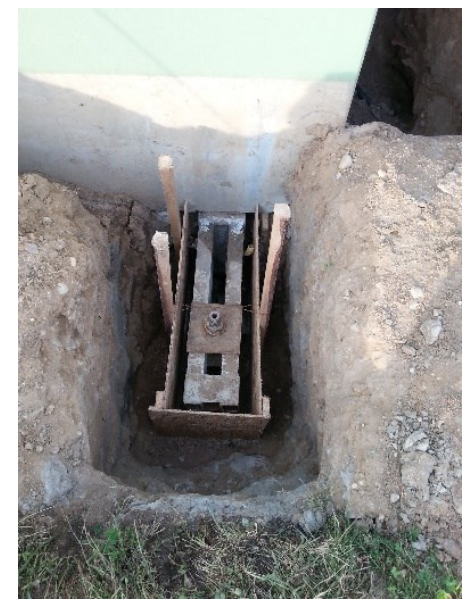

Fig. 13. Formwork for beams after rectification.

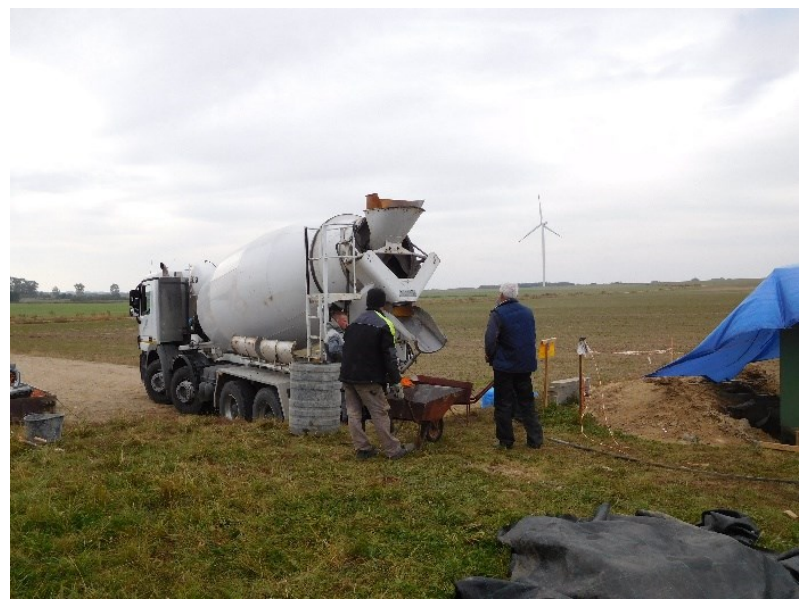

Fig. 14. Concreting.

$\checkmark$ Covering steel injection-tube beams in 6 points located under the bottom plate of the transformer station and at the transition points, this procedure involved 4 on the lifting side 2 on the opposite side,

$\checkmark$ Backfilling the excavations located around the station using the material originating from excavations, reconstruction of foil signs over cables - red on $\mathrm{sN}$ side, blue on the $\mathrm{nN}$ side and reconstruction of concrete edges on the concrete bench situated around the transformer station,

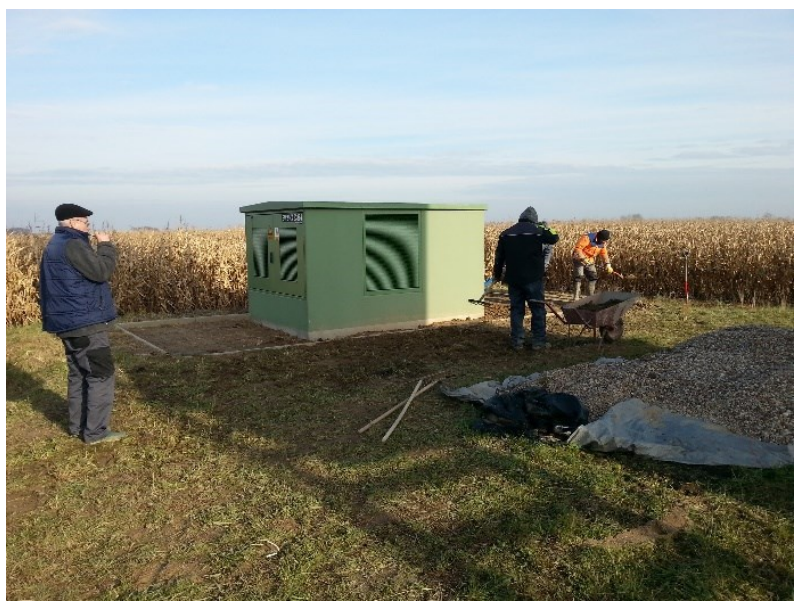

Fig. 15. Backfill after the repair.

$\checkmark$ Conducting the injection of cement paste $\mathrm{w} / \mathrm{c}=0.7$, this was done by installing the injection tubes previously covered with earth material. ANTIFROST 45 in an amount of $1 \%$ in relation to the cement mass was added during the mixing process. The average consumption of grout per one facility amounted to $400 \mathrm{dm} 3$ and the injection was conducted until one noticed the flow of liquid grout through the tubes placed on the opposite side of the station. 


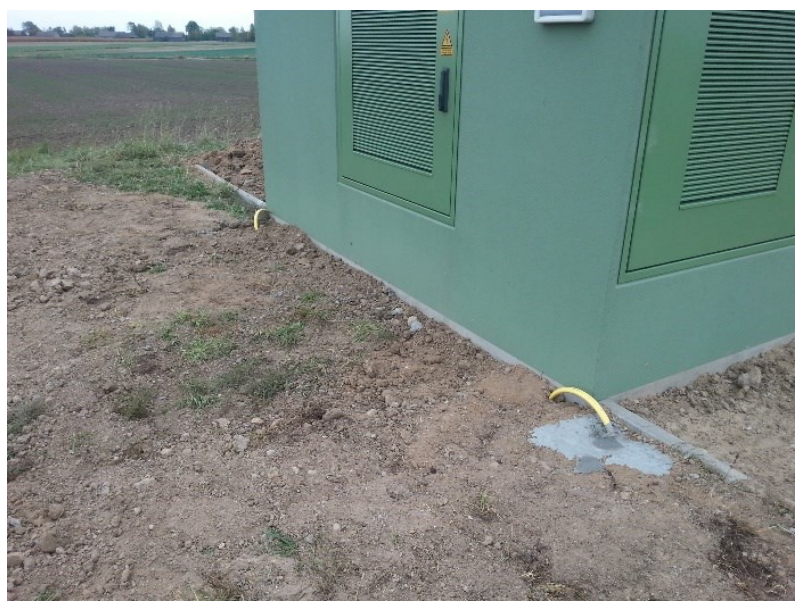

Fig. 16. Injection used to fill any voids under the plate.

$\checkmark$ Mechanical densification of the bank, manual levelling as regards the slopes and crowns of the bank, sowing grass.

$\checkmark$ The card below presents the course of the rectification process.

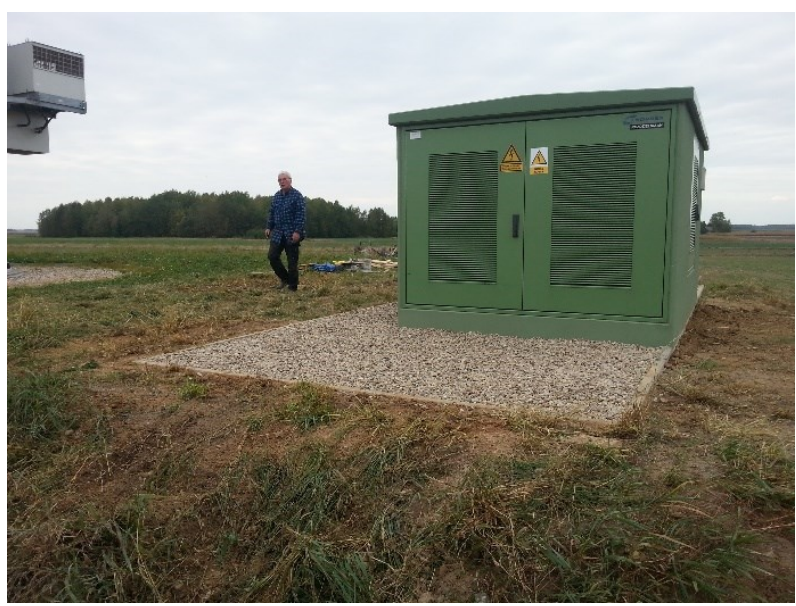

Fig. 17. Restoration of the work area after completing the works. 
Documentation on the course of the rectification process as regards the stabilization of transformer station no. EW5 foundations on a wind farm

\section{\begin{tabular}{l|l}
1 & Rectification
\end{tabular} \\ Person carrying out the rectification}

Manager of Works Krzysztof Walczak
Participants of rectification

Investor...

Project engineer

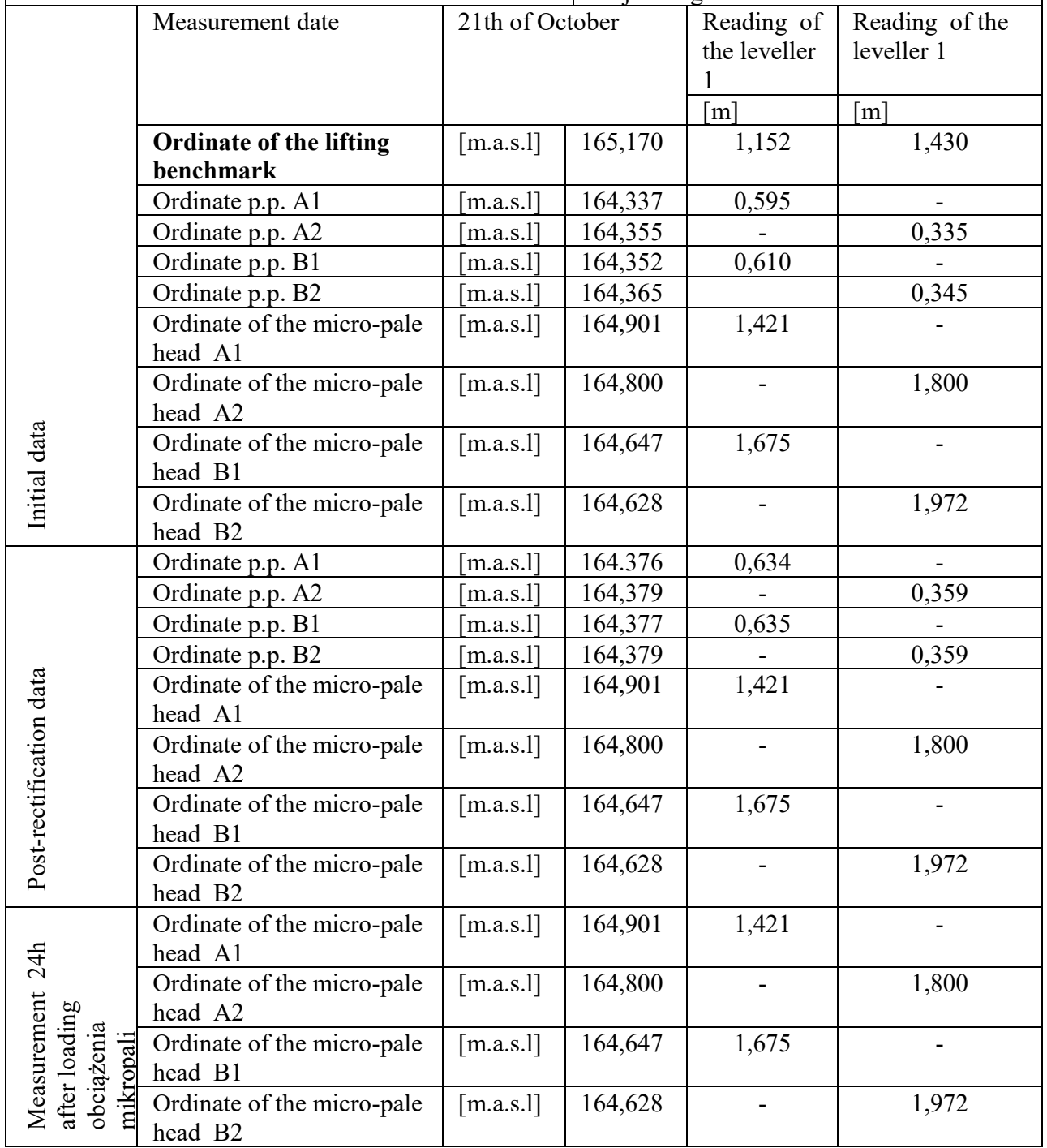

Fig. 18a. Card presenting the rectification process as regards the stabilization of transformer station foundations - Part A. 


\begin{tabular}{|c|c|c|c|c|}
\hline II & \multicolumn{3}{|c|}{ STABILIZATION } & \\
\hline Date of completing stabilization & \multirow{2}{*}{\multicolumn{2}{|c|}{03 November }} & $\begin{array}{l}\text { Technical } \\
\text { Supervision }\end{array}$ & $\begin{array}{l}\text { Krzysztof } \\
\text { Walczak }\end{array}$ \\
\hline Date of completing STABILIZATION & & & $\begin{array}{l}\text { Supervision } \\
\text { of the } \\
\text { author }\end{array}$ & Anna Gniwek \\
\hline $\begin{array}{l}\text { Manner of performing } \\
\text { STABILIZATION }\end{array}$ & \multicolumn{4}{|c|}{$\begin{array}{l}\text { Low-pressure to medium-pressure injection of cement } \\
\text { paste which was modified using admixture and anti- } \\
\text { corrosion additives designated for steel, made under the } \\
\text { foundation plate of the transformer station facility, } \\
\text { injection tubes placed and planted under the facility, on } \\
\text { both sides, after completion of rectification works and } \\
\text { after backfilling with cutting material }\end{array}$} \\
\hline Number of injection points & 6 & \multicolumn{3}{|c|}{ Arrangement on opposite sides of the facility } \\
\hline Max. Injection pressure & $\begin{array}{l}9 \\
\text { bar }\end{array}$ & \multicolumn{3}{|c|}{$\begin{array}{l}\text { Inspection based on the indication on pressure } \\
\text { gauge on the pump }\end{array}$} \\
\hline Injection equipment & \multicolumn{4}{|c|}{$\begin{array}{l}\text { Cement pump PTU-50, } 2 \text { mixing tanks, electric stirrer, } \\
\text { power generator }\end{array}$} \\
\hline Materials & \multicolumn{4}{|c|}{$\begin{array}{l}\text { CEM II } 32.5 \text { B-V cement, water from the aqueduct, } \\
\text { antisedimentiment and inhibitor additive }\end{array}$} \\
\hline Recipe as regards cement paste & \multicolumn{2}{|c|}{$\mathrm{w} / \mathrm{c}=0,7$} & \multicolumn{2}{|c|}{$\begin{array}{l}\text { Antifrost } 45-1 \% \text {, Admix } \\
\text { Powder }-0,5 \%\end{array}$} \\
\hline Control over the course of injection & \multicolumn{4}{|c|}{$\begin{array}{l}\text { Observation concerning manometer readings and } \\
\text { outflow of slurry from the opposite side of the tube than } \\
\text { side of injection }\end{array}$} \\
\hline The volume of the pumped slurry & \multicolumn{4}{|c|}{700} \\
\hline The weight of cement in the used slurry & \multicolumn{4}{|c|}{$700 \mathrm{~kg}$} \\
\hline $\begin{array}{l}\text { The weight of Antifrost in the used } \\
\text { slurry }\end{array}$ & \multicolumn{4}{|c|}{$7,5 \mathrm{~kg}$} \\
\hline The weight of Admix in the used slurry & \multicolumn{4}{|c|}{$3,8 \mathrm{~kg}$} \\
\hline The volume of water in applied slurry & \multicolumn{4}{|c|}{$525 \mathrm{dm}^{3}$} \\
\hline
\end{tabular}

Fig. 18b. Card presenting the rectification process as regards the stabilization of transformer station foundations - Part B.

\section{Summary}

Tilting of 9 transformer station objects was affirmed by measurement and was caused by uneven settlement of the substrate which, in turn, resulted from uneven settlement of the ground below the foundation level. Such a situation required rapid geo-engineering activities aimed at discontinuing the process involving uncontrolled subsidence and restoring the facilities to the vertical and horizontal positions assumed in the project.

Conducted rectification of 9 transformer stations resulted in full restoration of the utility value as regards the facilities. What is most significant, it enabled preventing a failure. The works were conducted in such a manner that the exclusions/downtimes concerning individual transformer stations were as brief as possible.

The repair work was not easy. The mere concept of conducting this task required a detailed analysis in reference to the design as well as as-built documentation covering the construction of the wind farm.

One should bear in mind that even when dealing with such immense and expensive investments as building a wind farm, one can come across errors and rectifying them when facility/investment is already operating absorbs additional financial means. The described situation result not only from construction works but from downtime concerning particular transformer stations/ wind turbines as well. 


\section{References}

1. Report: Ekspertyza geotechniczna posadowienia stacji transformatorowych turbin wiatrowych (HGS, Warszawa, 2015) [in Polish]

2. Design project: Projekt wykonawczy rektyfikacji fundamentów trafostacji (HGS, Warszawa, 2016) [in Polish]

3. Design project: Dokumentacja powykonawcza rektyfikacji fundamentów trafostacji (HGS, Warszawa, 2016) [in Polish]

4. PN EN 14199:2008 Wykonawstwo specjalnych robót geotechnicznych - mikropale [in Polish]

5. PN-EN 1997-1:2008 Eurocode 7: Geotechnical Design, Part 1: General rules

6. PN-B-03020:1981: Grunty budowlane. Posadowienie bezpośrednie budowli. Obliczenia statyczne i projektowanie [in Polish] 